\title{
ISOLATION AND BIOCHEMICAL CHARACTERIZATION OF PHOSPHATE SOLUBILIZING MICROBES
}

\author{
MAHANTESH P. AND PATIL C.S.* \\ Department of Biotechnology B.V.Bhomraddy College, Bidar, Karnataka \\ * Corresponding Author: Email- drcspatil1251@yahoo.co.in, drcspatil1960@gmail.com
}

Received: March 12, 2011; Accepted: April 23, 2011

\begin{abstract}
Phosphorus $(P)$ is one of the essential macronutrients for plant growth and reproduction. Plants acquire $P$ from the soil solution as phosphate anions. However, phosphate anions are extremely reactive and may be immobilized through precipitation with cations such as $\mathrm{Ca} 2+, \mathrm{Mg} 2+, \mathrm{Fe} 3+$ and $\mathrm{Al} 3+$, depending on the particular properties of the soil and as a result, the phosphate is highly insoluble and unavailable to plants. Application of phosphate-solubilizing fungi (PSF) has been added as fertilizer to increase P uptake and plant growth. The improvement of soil fertility is one of the most common strategies to increase agricultural production. Maintaining high levels of available nitrogen $(\mathrm{N})$ and phosphorus $(P)$, the two most limiting nutrients in soil, remains being a challenge.

Major researches on biofertilizer have concentrated on understanding and improving N2 fixation. However, it is known that every aspect of the process of nodule formation is limited by the availability of $P$. Legumes like alfalfa and clover show a high positive response to $\mathrm{P}$ supplementation (Gyaneshwar et al., 2002), but most of the supplemented $\mathrm{P}$ become unavailable when its reacts with soil components.

Many soil microorganisms are able to solubilize this unavailable $\mathrm{P}$ through their metabolic activities exudating organic acids, which directly dissolve the rock phosphate, or chelating calcium ions that release $\mathrm{P}$ to the solution. Production of microbial metabolites results in a decrease in soil pH, which probably plays an important role in the solubilization (AbdAlla, 1994).

Phosphate solubilizing bacteria (PSB) were isolated from the area around Bidar region and screened on the basis of their solubilization of inorganic tricalcium phosphate in liquid cultures. Ten strains that had higher solubilization potential were selected, and they characterized.
\end{abstract}

Key words: Phosphate solubilizing microbes; phosphorous; Soil phosphorus; Solubilization

\section{INTRODUCTION}

Phosphorus $(P)$, after nitrogen is the major plant growth-limiting nutrient despite being abundant in soils in both inorganic and organic forms. Chemical fertilizers added to the soils to circumvent the problem of $\mathrm{P}$ deficiency, further compound the situation by the fact that almost $75-90 \%$ of added $P$ fertilizer is precipitated by $\mathrm{Fe}, \mathrm{Al}$ and $\mathrm{Ca}$ complexes present in the soils (Gyaneshwar et al. 2002). Phosphorus biofertilizers in the form of micro-organisms can help in increasing the availability of accumulated phosphates for plant growth by solubilization (Ryu, J.H et al. 2006). Individual or co-inoculation of PSB with other groups of microorganisms enhanced the plant growth by increasing the efficiency of biological nitrogen fixation or the availability of other trace elements and by the production of plant growth promoting (PGP) substances (Poonguzhali, $\mathrm{S}$ et al. 2005). To isolate and characterize the phosphate solubilizing bacteria (PSB) associated with the rhizosphere of Chinese cabbage (Brassica campestris sub sp. pekinses), using tri-calcium phosphate (TCP) as the insoluble phosphate source.

Phosphorous is essential for growth and productivity of plants. It plays an important role in plants in many physiological activities such as cell division, photosynthesis, and development of good root system and utilization of carbohydrate. Phosphorous deficiency results in the leaves turning brown accompanied by small leaves, weak stem and slow development. In ancient times the use of animal manures to provide phosphorous for plant growth was common agricultural practice. Organically bound phosphorous enters in soil during the decay of natural vegetation, dead animals and from animal excretions. At that time role of micro flora on soil fertility was hardly understood.

Assimilation of phosphate from organic compounds by plants and microorganisms take place through the enzyme "phosphatase" which is present in a wide variety of soil microorganisms. Plant can absorb phosphate only in soluble form. The transformation of insoluble phosphate into soluble form is carried out by a number of microbes present in the soil. A large fraction of soil microbes can dissolve insoluble inorganic phosphates present in the soil and make them available to the plants.

The medium (Sperbre 1958) used to estimate the population density of phosphate solubilizers show a 
clear zone around the colonies indicating phosphate solubilization. Phosphate cleaved by the enzyme phosphatase secreated by phosphate solubilising bacteria was performed according to Tabatabai and Bremner (1969).

\section{MATERIALS AND METHODS \\ Collection of soil samples:}

Soil samples were collected from neighboring cultivated area of Bidar, Karnataka. Collection of soil samples was made at a depth of $10 \mathrm{~cm}-15 \mathrm{~cm}$ from 6 different points within the area. The samples were than air-dried and mixed well to isolate single Bacterial sample. The sample was then taken for the study.

\section{Isolation of strains:}

10 grams of air-dried powdered soil was taken in to $100 \mathrm{ml}$ sterilized distilled water and shaken for 15 minutes. Subsequent dilution was made following the technique of Alexander (1965) for serial dilution technique.

For inoculation $1 \mathrm{ml}$ of the soil dilution was taken as an inoculum in the plate and media was poured in to it. Then the inoculated plates were incubated in an incubator at $30 \mathrm{C}$ for 24 hours. Isolated the bacterial strains into agar slants of respective medium from morphologically different colonies. Repeated sub cultures were made to get the pure culture. Isolated bacteria are designated as B1, B2, B3.........B8.

\section{Most probable number estimation of Phosphate solubilize:}

Most probable number estimation was made according to Alexander (1965) as follows: 10gms of air-dried soil was mixed with $100 \mathrm{ml}$ sterilized distilled water in a $250 \mathrm{ml}$ flask. The flask was shaken for 10-15 minutes. The subsequent dilutions were made by diluting $10 \mathrm{ml}$ of each of the previous dilution into $90 \mathrm{ml}$ water, which gives $10^{1}, 10^{2}, 10^{3}, 104,105$ and subsequently dilutions respectively.

The population densities of organisms were estimated by inoculating 5 replicates for each dilution with $1 \mathrm{ml}$ of respective dilution. Dilutions were made until a readable count was obtained. The population density was estimated through Alexander chart (1965).

The results are given in the Fig-1. MPN was estimated in two different medium and the numbers of colonies were recorded more in Pikovskaya agar medium than the calcium phosphate medium.

\section{Phosphate activity of soil:}

To $1 \mathrm{gm}$ of the soil $4 \mathrm{ml}$ buffer (ph 6.6) was added. After shaking well $1 \mathrm{ml}$ of paranitrophenol phosphate solution was added. The flask was swirled for few seconds to mix the contents.

Than the flasks were stoppered and placed in an incubator at $37 \mathrm{C}$ for 1 hour. After 1 hour incubated 1 $\mathrm{ml}$ of Calcium chloride solution and $4 \mathrm{ml}$ of sodium hydroxide was added. The flask was shaked properly. After mixing well the content was filtered through
Whatman No 40 filter paper. The colour of the filtrate was read colorimetrically at $410 \mathrm{~nm}$.

The results are given in Table-2. para-nitrophenol phosphate was used to draw the standard curve. For this study three types of soil samples were taken. They are (i) Cultivated soil, (ii) Acidic contaminated soil and (iii) Virgin soil. The phosphatase activity of soil microbes were found more in cultivated soil than the other two samples.

\section{Characterisation of strain (Biochemical Characterization)}

It is not possible to study all the biochemical characters to identify the bacteria within a small period of one month. Therefore, most essential characters such as microscopic study, starch hydrolysis capability, catalase activity, Methyl red test, citrate utilization, nitrate reduction activity, etc. of the isolated bacteria were determined. Characterisations were made following microbiology, a laboratory manual (Cappucino and Sherman, 1982).

(a) Microscopic study: The most important differential stain used in bacteriology is the Gram stain. It divides the bacteria into two major groups: gram positive and gram negative. Four different reagents are needed for this study. They are crystal violet, mordant Gram's iodine, Decolorizing agent Ethyl alcohol and counterstain safranin.

(b) Starch hydrolysis: Starch is a complex carbohydrate. All the bacteria cannot utilize it. Nonutilization of starch imparts a blue coloration with iodine to the medium.

(c) Citrate Utilization: Certain bacteria are capable of utilizing citrate as an organic carbon source. Growth of the stain in the medium can be detected visually. The composition of the medium was as follows: Sodium citrate: 3gm, Potassium Di-hydrogen phosphate: $1 \mathrm{gm}$, Magnesium sulphate: $0.2 \mathrm{gm}$, Sodium hydrogen phosphate: $1.5 \mathrm{gm}$, Distilled water: 1 Litre.

(d) Hydrogen Sulhite Test: Some bacteria have the ability to produce hydrogen sulphite fron substrates like sulphur containing amino acids or any sulphur containing compounds. The medium was prepared with the following compounds: Di-Potassium hydrogen phosphate: 2gms,

Sodium: 1gm, Sodium thiosulphate: 1gm, Glucose: $1 \mathrm{gm}$, Magnesium sulphate:0. 8gm, Ferrous sulphate:0. 024ml, Distilled water: 1Litre. Black precipitate of sulphide will indicate sulphide formation ability by the stains.

(e) Nitrate reduction test: Some microorganisms can reduce nitrates to nitrites or beyond nitrite stage. The medium for this test was prepared as follows: Potassium nitrate: 1gm, Beef extract: 3gms, Peptote: $5 \mathrm{gms}$, Distilled water: 1Litre. After incubation a few 
drops of reagent I (8 gms of Sulfanilic acid in $5 \mathrm{~N}$ acetic acid), and reagent II (5 gms of -napthol amine in 1 litre of $5 \mathrm{~N}$ acetic acid). A distinct pink or red colour will indicate the reduction of nitrate.

(f) Catalase test: This test was performed to determine the ability of the strains to degrade hydrogen peroxide by producing enzyme,catalase or peroxidase. The test was made by putting a drop of $20 \%$ hydrogen peroxide on a clean glass slide and emulsified by a little culture in it.

Presence of air bubbles indicates the activity of catalase.

\section{RESULTS AND DISCUSSION}

In the present study 32 soil samples were collected from different villages of Bidar, Karnataka 8 samples showed presence of PSM. The bacterial strains producing zone of P-solubilization after 48h incubation on Pikovskaya agar, the bacterial strains were characterized for Gram staining, Starch hydrolysis, Citrate utilization; Hydrogen Sulphite production, Nitrate reduction, Catalase Test, Nitrogen fixation, and the results were shown in table. The Most Probable number of colonies were estimated on different medium and shown in table. According to the laboratory experiment of phosphate solubilization, it was found that most of colonies were found in Pikovskaya agar medium compared to calcium phosphate medium and the results shown in figure.

\section{REFERENCES}

[1] ABD-Alla M.H. (1994) Letters in Applied Microbiology, 18, 294-296.

[2] Evans C.G.T., Herbert D. and Tempest D.B. (1970) Methods in Microbiology, 2, 277-327.

[3] Fiske C.H. and Subbarow Y. (1925) Journal of Biological Chemistry, 66, 375-400.

[4] Goldstein A.H. (1995) Biological Agriculture and Horticulture, 12, 185- 193.

[5] Gyaneshwar P., Naresh K.G., Parekh L.J., Poole P.S. (2002) Plant Soil 245, 83-93.

[6] Herrera-Cervera J.A., Caballero - Mellado J., Lagguerre G., Tichy H.V., Reqyena N., Amarger N., Martinez -Romero E., Olivares J. and Sanjuan J. (1999) FEMS Microbiology Ecology, 30, 87-97.

[7] Murphy J., Riley J.P. (1962) Anal. Chim. Acta 27, 31-36.

[8] Poonguzhali S., Madhaiyan M., Thangaraju M., Ryu J.H., Chung K.Y., Sa T.M. (2005) J. Microbiol. Biotechnol. 15, 903-908.

[9] Ryu J.H., Madhaiyan M., Poonguzhali S., Yim W.J., Indiragandhi P., Kim K.A., Anandham R., Yun J.C., Sa T.M. (2006) J. Microbiol. Biotechnol.16, 1622-1628. 
Table 1- Bacterial Characterization

\begin{tabular}{|c|c|c|c|c|c|c|c|c|}
\hline Organism & Gram staining & Shape & A & B & D & $E$ & $F$ & G \\
\hline B1 & - & Cocci & + & - & + & + & - & + \\
\hline B2 & + & Cocci & + & + & + & + & + & + \\
\hline B3 & - & Chain & + & + & + & + & - & - \\
\hline B5 & - & Rod & - & + & - & - & + & + \\
\hline B6 & + & Cocci & + & V & + & + & - & + \\
\hline B7 & - & Cocci & + & - & - & + & - & + \\
\hline B8 & - & Chain & + & + & - & + & + & + \\
\hline
\end{tabular}

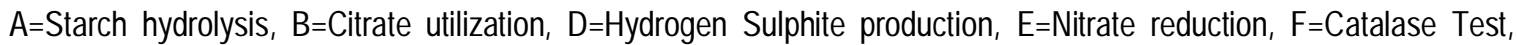
$\mathrm{G}=$ Nitrogen fixation

Table 2-Phosphatase activity of soil microbes (IN NEUTRAL MEDIUM)

\begin{tabular}{|l|c|}
\hline \multicolumn{1}{|c|}{ Sample } & Mg of para nitrophenyl/gram soil \\
\hline Cultivated soil (garden soil) & 0.99 \\
\hline Contaminated soil (acidic soil) & 0.23 \\
\hline Virgin soil & 0.72 \\
\hline
\end{tabular}

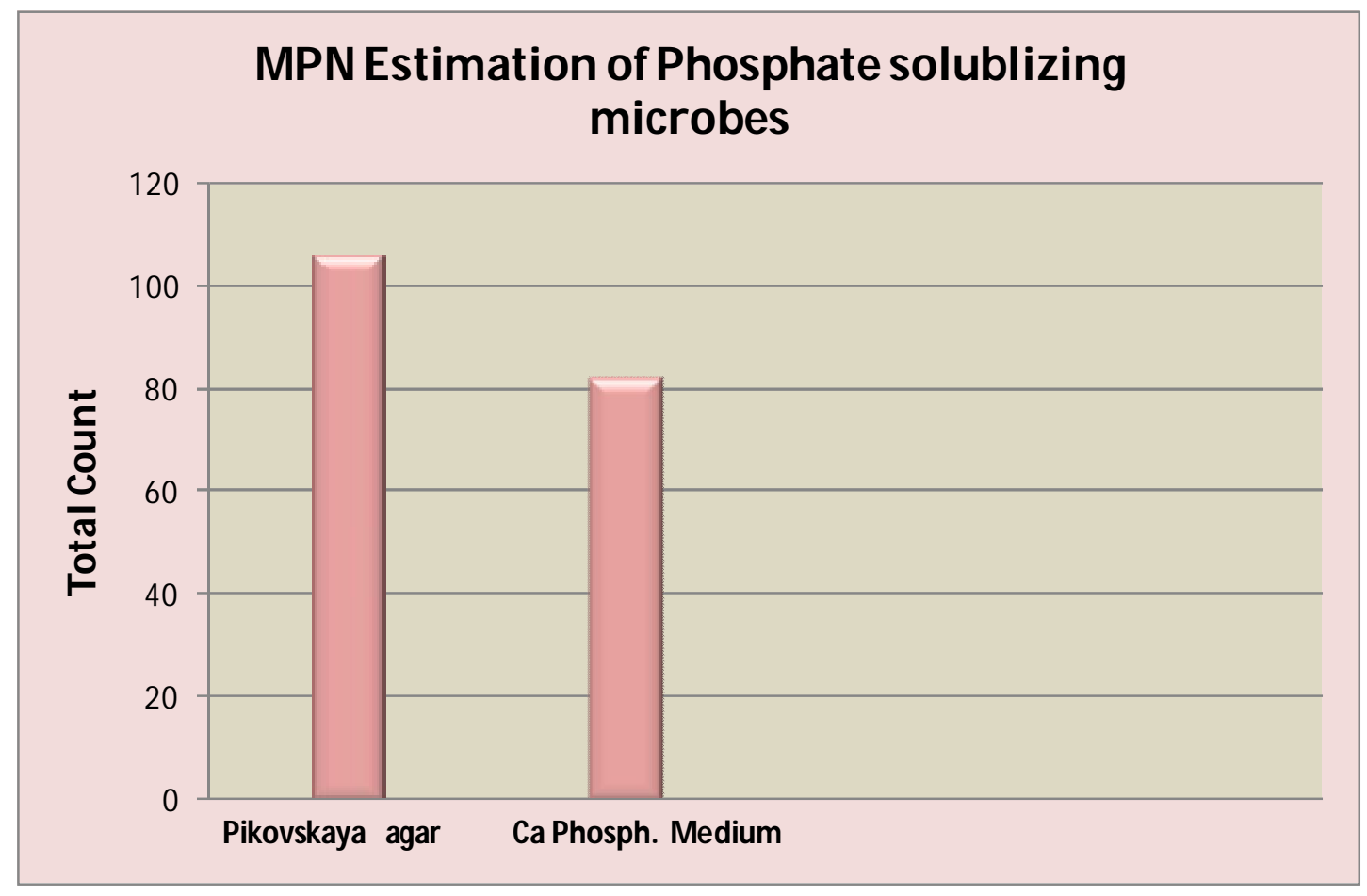

Fig. 1- Most Probable number estimation of P-Solublizing Microbes 